\title{
Diethyl thiourea as a cause of dermatitis in a car factory
}

\author{
W. G. WHITE and H. R. VICKERS \\ British Leyland (Austin/Morris) Ltd., Cowley Division, Oxford and the \\ United Oxford Hospitals, Oxford
}

\begin{abstract}
White, W. G., and Vickers, H. R. (1970). Brit. J. industr. Med., 27, 167-169. Diethyl thiourea as a cause of dermatitis in a car factory. Fifteen car assembly workers became sensitized to self-skinning neoprene foam weather strips by contact with the bare forearms for the greater part of the working day. A series of patch tests showed 11 out of 11 tested to be sensitive to diethyl thiourea present in the neoprene as an accelerator. The condition cleared on modification of the assembly process.
\end{abstract}

In the last quarter of 1968, the nursing staff in a car assembly factory reported to one of us (W.G.W) that there was a marked increase in the number of men reporting to the works hospital with irritable rashes affecting particularly the hands and forearms and, in a few instances, the face.

Having experienced trouble in 1962 and 1963 with dermatitis caused by an anti-oxidant/anti-ozonant (Nonox ZA) present both in rubber gromets and in windscreen washer tubing, we were struck by the similarity between these two groups of cases. In 1962 and 1963 the cause had been found by patch testing and the condition had cleared when the offending substances had been eliminated from the rubbers handled. In this present outbreak all the men complained of irritation on the hands and the flexor aspect of the forearms and some complained of irritation of the face.

On examination there were well-defined, slightly raised, erythematous macules scattered on the anterior aspects of both forearms in all cases, and some men complained of irritation of the face associated with erythematous patches which fluctuated throughout the weeks of observation. Others had areas of dermatitis on other parts of the body which came into contact with rubber depending on the working conditions, e.g., one shoulder, the back of the legs, etc. In all, 15 men were affected.
The car body shells are supplied by another division of the group where both door and bonnet sealing strips are applied, but no similar skin troubles had been reported at that factory. Some of the men who were affected attached various components to the body shell and, in so doing, their bare forearms to a greater or less extent came into contact with the rubber weather strips around the bonnet opening. Similarly, mechanics who tuned the engine also came into contact with this sealing strip (Figure) and two men working through the door opening came into contact with the rubber sealing strip of the door opening.

It therefore seemed probable that the cause of the dermatitis was in the rubber used in the bonnet and door seals. Patch tests using a piece of the rubber were applied to eight of the men and seven gave positive reactions; six of these men were also tested with a different type of sponge rubber and each gave a negative reaction to this.

The manufacturers of the bonnet sealing strip were very co-operative in trying to solve this problem. Their technical representatives visited the assembly line and supplied a whole series of test samples from which different constituents had been left out, to try to find the causative constituent. Nine men were tested to six different samples and to the powder which covered the rubber. All except 


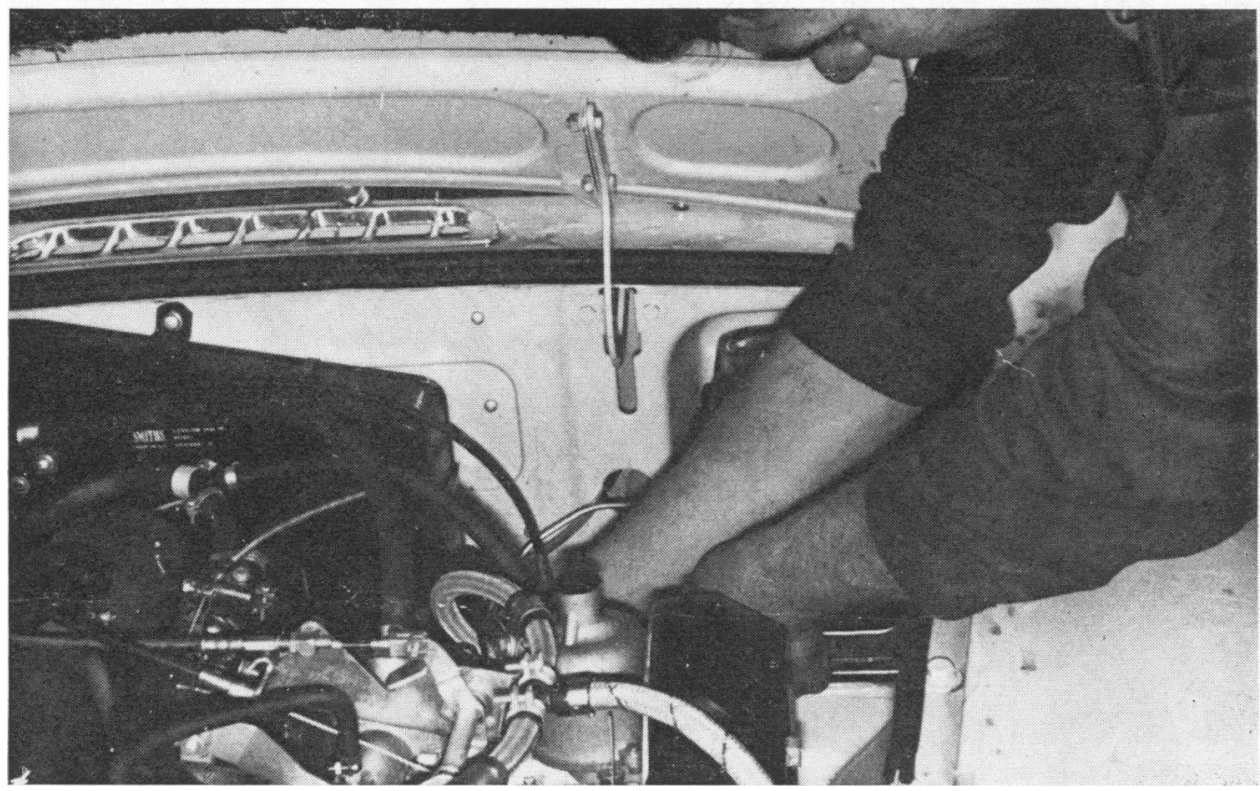

FIGURE. Worker with bare forearms in contact with weather sealing strip.

one gave positive reactions of varying degree to the samples; none reacted to the powder. The one nonreactor showed mild erythema to two of the six patches applied. It was therefore obvious that the offending substance was present in all the samples supplied by the manufacturers.

The manufacturers then supplied samples of the ingredients, and suitable dilutions in medicinal liquid paraffin were applied to 11 individuals and in addition tests using crude neoprenes were done. The patches were applied under $2 \times 2$ in. Johnson and Johnson Band-Aid dressings and these were read after 48 hours. All 11 men reacted positively to diethyl thiourea and one gave faint erythema to three other tests; and all gave negative reactions to the other ingredients, including ethylene thiourea. This proved beyond reasonable doubt that the accelerator, diethyl thiourea, was the cause of the trouble in this particular outbreak. All the rubber referred to is a self-skinning neoprene foam.

\section{Discussion}

Engel and Calnan (1963) described a similar outbreak of dermatitis in a motor car factory which was shown to be due to paratertiary butyl phenol formaldehyde resin used in an adhesive. In our cases, no adhesive was being used; the rubber strips were held in place by spring clips embedded in the rubber during the moulding process. One possible cause that was considered was the deposit of powder remaining on the surface of the rubber following the extrusion process. This powder consists of a mixture of sodium and potassium nitrate and nitrites but patch testing to this was negative in all cases.

Since rubber containing diethyl thiourea has been shown to be a potent sensitizer in our patients, it is of interest that no cases occurred in the factory in which the rubber seals were fitted. This is probably due to the difference in thickness of the horny layer of the palms in the men who fit the seals and the horny layer of the forearms in those who come into casual contact with the rubber in the course of other manoeuvres. Before the actual causal ingredient was found, and after rubber was suspected, it was necessary to try to eliminate contact with the rubber. The men were encouraged to work with their sleeves not rolled up and the rubber was covered with masking tape before the assembly process started. Later the process was altered so that the bonnet rubber seal was fitted after assembly had been completed. It was not possible, however, to cover the door seal but only one operative was affected by this and he was advised to work with his sleeves down; his rash cleared quickly with a fluorinated corticosteroid cream.

Special efforts have been made to ensure that the operators practise recommended methods of washing and do not use harsh cleaners and solvents. It is a great credit to the sensitized individuals concerned that, after the problem of trying to find the cause had been explained to them, they co-operated willingly in repeated patch tests, for without this 
co-operation it would have been impossible to find the cause of the outbreak.

We agree with Engel and Calnan that the only real solution to such a problem is to replace the offending material by a non-sensitizing substitute. It is not always possible to replan the assembly of the body so that the order of work can be altered, but in this case it was possible to make the modification of applying the bonnet seal at the end of the process, thereby helping to control the outbreak, which settled down in subsequent weeks.

By reporting potential sensitizers it is hoped that manufacturers will avoid using them in the future. Unfortunately prophetic screening is not possible since the state of sensitization can be established only by repeated contact with the potential sensitizer.

Subsequent enquiries have brought to light an outbreak of conjunctivitis in workers in the manufacture of rubber sealing strips which also utilize diethyl thiourea in the mix (Groves and Smail, 1969).

We should like to thank Sister Fraser, the nursing staff and employees of the M.G. Division of British Leyland (Austin/Morris) Ltd., for their help and co-operation, as well as Dr. H. G. Parkes of the British Rubber Manufacturers' Association Ltd. and several rubber manufacturers including Capon Heaton \& Co. Ltd., Draftex Ltd., and Dupont Ltd.

\section{References}

Engel, H. O., and Calnan, C. D. (1963). Chromate dermatitis from paint. Brit. J. industr. Med., $20,192$.

Groves, J. S., and Smail, J. M. (1969). Outbreak of superficial kersatitis in rubber workers. Brit. J. Ophthal., 53, 683-687.

Received for publication August 18, 1969. 